\title{
Representaciones mediáticas y migración: análisis de discursos periodísticos respecto al coyotaje en la «crisis migratoria» de 2014
}

The media and migration: an analysis of journalistic discourses regarding smuggling in the context of the «immigrantion crisis» of 2014

Eduardo Torre Cantalapiedra* ISSN IMPRESO 1870-7599 | ISSN RED CóMPUTO 2448-7783 | 157-178

Resumen. El objetivo de este trabajo es analizar las representaciones sobre el coyotaje en los discursos periodísticos informativos respecto a la migración en tránsito irregular por México. Con base en 281 textos relativos a la transmigración centroamericana en los periódicos El Universal y Reforma se examinan las representaciones mediáticas en torno al coyotaje y los coyotes en el contexto de la "crisis migratoria» de 2014, se considera la intertextualidad en los discursos periodísticos y la forma en que se ejerce el periodismo.

Palabras clave: migración internacional, migrantes centroamericanos, coyotes, discurso periodístico, representaciones.

Abstract. The goal of this paper is to analyze the media representations regarding migrant smuggling in the journalistic discourses and reporting regarding irregular migration from Mexico. Based on 281 texts on Central American migration in the El Universal and Reforma news organizations, it examines the media representations of smuggling generally and in the context of the migratory crisis of 2014, taking into account the intertextuality of the journalistic discourses and the way in which journalism is practiced.

Keywords: international migration, Central-American migrants, coyotes, journalistic discourse, representations.

* Becario del Instituto de Investigaciones Jurídicas, Programa de Becas Posdoctorales en la Universidad Nacional Autónoma de México, asesorado por el doctor Enrique Mauricio Padrón Innamorato.

Es necesario reconocer a la Hemeroteca Nacional de México por su labor de conservación y su disposición por difundir al público el material periodístico que posibilita la realización de investigaciones académicas como la presente. Asimismo, se agradece a Dulce María Mariscal por sus comentarios a una versión anterior del trabajo y a los dictaminadores anónimos por sus sugerencias. 



\section{Introducción}

Desde los 1990 el coyotaje $^{1}$ ha sido una actividad imprescindible para entender el fenómeno de la migración en tránsito hacia Estados Unidos. ${ }^{2}$ Aunque se carece de cifras precisas sobre el fenómeno del uso de coyotes, ${ }^{3}$ puede afirmarse que decenas de miles de migrantes mexicanos y centroamericanos han solicitado sus servicios para desplazarse al territorio estadounidense. Sin embargo, la investigación concerniente al funcionamiento de tal actividad ha sido limitada, particularmente en cuanto a la migración centroamericana en tránsito irregular por México. Este déficit de conocimiento se debe en gran medida al carácter subrepticio y elusivo del tráfico de personas, por tratarse de una actividad que los Estados sancionan en sus legislaciones. ${ }^{4}$

No ha sido el coyotaje el único interés académico. Dado que las notas periodísticas y otros textos de carácter informativo configuran un universo de discursos que simbolizan los fenómenos migratorios y a sus protagonistas, al constituir una gran parte del conocimiento de sentido común que los ciudadanos tienen sobre los mismos, su análisis respecto a la migración resulta fundamental. El número de trabajos que han abordado representaciones y discursos mediáticos referentes al coyotaje y los coyotes, incluidas las contribuciones que lo hacen tangencialmente, es reducido (véase Nash, 2005; Spener, 2008; Simone y Aierbe, 2010). Se han examinado discursos periodísticos en países receptores de migrantes tomando en cuenta los siguientes tópicos: la manera en que representan la actividad del coyotaje y a los coyotes, los actores sociales cuyas voces son dominantes en los discursos de tal actividad, las malas prácticas periodísticas, entre otros.

${ }^{1}$ En este trabajo se consideran sinónimos los términos «coyotaje», «contrabando de personas» y «tráfico de personas». De igual manera se emplean como sinónimos "coyote», «pollero», "traficante de personas» $y$ "contrabandista de personas». Para facilitar la lectura se utilizan los términos «coyotaje», "coyote» $\mathrm{y}$ «pollero» en cursivas, en vez de emplear entrecomillado.

${ }_{2}^{2}$ Andreas (2001) advierte que el tráfico de personas y su persecución han crecido sustancialmente desde los 1990 .

${ }^{3}$ Cabe valorar algunas aproximaciones cuantitativas al fenómeno: París (2016) efectúa estimaciones con base en la Encuesta sobre Migración en la Frontera Sur 2013; Dolfin y Genicot (2009) utilizan datos de 118 comunidades del Mexican Migration Project (MMP).

${ }^{4}$ Por ejemplo, la Ley de Migración mexicana de 2011 impone penas de prisión y elevadas multas a quienes desarrollen actividades de coyotaje en el territorio mexicano (véase Congreso de la Unión de los Estados Unidos Mexicanos, 2017:artículo 159). 
El propósito de la investigación es profundizar en las representaciones sobre el coyotaje y los coyotes en los discursos periodísticos informativos sobre la migración en tránsito por México. Se organiza en cuatro secciones: en la primera se presentan los elementos teóricos que guían el estudio; en la segunda se lleva a cabo una sucinta revisión abocada al fenómeno del coyotaje desde los estudios de los medios de comunicación de masas; en la tercera se exponen el corpus de textos informativos empleado y algunas cuestiones metodológicas relevantes - delimitar el análisis al año 2014 responde a la prominencia que en los medios de comunicación tuvo la denominada crisis de los niños, niñas y adolescentes migrantes (NNAM), un terreno fértil para indagar las representaciones mediáticas sobre el coyotaje - ; en la cuarta, con base en la revisión de 281 textos informativos - noticias, crónicas, entrevistas, testimonios y reportajes - de los diarios El Universal y Reforma, relativos a la transmigración centroamericana irregular, se examinan las representaciones sobre el coyotaje y los coyotes en los discursos periodísticos en el contexto de la crisis de los NNAM de 2014, se consideran la intertextualidad en tales escritos y la forma en que se ejerce el periodismo.

\section{Marco analítico}

Representaciones mediáticas y la construcción de la realidad social

Rodrigo Alsina indica que la «noticia es una representación social de la realidad cotidiana producida institucionalmente que se manifiesta en la construcción de un mundo posible» (1989:13). Afirma que la noticia se genera a partir de la selección de acontecimientos por parte de la institución informativa legitimada para producir realidad socialmente relevante — doble institucionalidad de medios de comunicación de masas - y que es una producción discursiva que posee un proceso de elaboración textual. Por lo tanto, los medios desempeñan un papel fundamental en la construcción social de la realidad al asumir una función esencial en la mediación simbólica; deciden qué acontecimientos son importantes — «merecen» ser noticia—y originan representaciones sociales de la realidad que son compartidas.

Para examinar en mayor detalle la labor de los medios de comunicación de masas en la construcción social de la realidad, es indispensable considerar el modelo de Adoni y Mane (1984). De acuerdo con estas autoras, el proceso dialéctico 
de construcción de la realidad social puede entenderse como un sistema compuesto por dos dimensiones: los tipos de realidad social (objetiva, simbólica y subjetiva) y la distancia de sus elementos con las experiencias de los individuos en la vida cotidiana. El esquema de Adoni y Mane (1984) permite reparar en que los medios de comunicación no son la única fuente de construcción de realidad social (Alsina, 1989), se trata sólo de una de las realidades que construimos, la informativa. Asimismo, posibilita reflexionar en torno de la trascendencia que tienen los medios de comunicación y la realidad social simbólica que construyen cuando cubren acontecimientos situados lejos de las experiencias de la vida cotidiana de los individuos.

Dado que el tránsito irregular de migrantes se caracteriza por su afán de invisibilidad —en particular el apoyado por coyotes - y puesto que muchos sujetos no tienen experiencia directa con tales prácticas migratorias en su vida cotidiana - se sitúan hacia las zonas de relevancia remotas-, puede suponerse que las representaciones que los medios hacen sobre el coyotaje, en este caso la prensa, son sustanciales en la construcción de realidad social acerca de dicho fenómeno.

\section{Intertextualidad y ejercicio de la profesión periodística}

Los discursos periodísticos informativos se caracterizan por recuperar los discursos de otros actores sociales, aunque de manera fragmentaria. Una de las expresiones más obvias de esa intertextualidad se produce cuando en un texto se rescatan las voces de distintos actores mediante la citación (Genette, 1989). Esta herramienta permite plasmar los diferentes puntos de vista de los implicados en los acontecimientos. Tales actores son las fuentes de información de los periodistas, porque los limitados recursos impiden que éstos observen y analicen de primera mano todos los sucesos (De Fleur y Ball-Rokeach, 1993). Para una comprensión cabal sobre cómo la prensa escrita recobra los discursos ajenos para la generación de sus textos periodísticos, resulta esencial conocer el papel social del periodista y la forma en que ejerce su profesión.

De acuerdo con Rodrigo Alsina (1989) el periodista cumple una labor institucionalizada y legitimada de ser transmisor del saber cotidiano y traductor del conocimiento de los expertos para el gran público. A partir de tal referencia y de Rodrigo Alsina y Gaya Morla (2001) es posible afirmar que los periodistas deben reunir las siguientes características: 1. poseer una amplia base cultural, pero no necesariamente ser expertos en las materias sobre las que escriben; 2 . seleccionar 
los acontecimientos que se consideran relevantes desde el punto de vista periodístico; 3. buscar la objetividad, aunque no puedan alcanzarla a cabalidad debido a la presencia de grandes obstáculos; 4. redactar las noticias con las restricciones del proceso productivo en el que se hallan; 5. trabajar con limitaciones de tiempo, por ello no pueden detenerse en detalles; 6 . producir de manera comprensible para amplias audiencias, por lo que utilizan los marcos de referencia de éstas y suelen aproximarse a los sucesos con el empleo de interpretaciones hegemónicas.

Cabe mencionar la tipología de formas de ejercer la profesión según Caminos Marcet (1997), quien distingue entre periodismo de rutina y periodismo de investigación. La primera tipología se ejerce cuando el periodista adopta una posición pasiva respecto a las fuentes de información y permanece a la espera de que las mismas le suministren datos. Destaca dos razones que provocan esa conducta: el hecho de que organismos e instituciones dispongan de mecanismos para controlar las informaciones que generan en grandes cantidades y que les son beneficiosas; y que los cambios tecnológicos han modificado la práctica periodística, lo que ha supuesto que los periodistas pasen más tiempo en las redacciones. La segunda tipología se caracteriza por buscar la verdad oculta, no apoyarse en fuentes de información oficiales y recelar de ellas, basarse sólo en datos ampliamente contrastados. Puesto que el primer modo de hacer periodismo es el más generalizado, no es de extrañar que las fuentes oficiales sean referidas en los textos de los periodistas con mucha mayor frecuencia que otras (Rodrigo, 1989; Castagnani y Colorado, 2009). Con base en dicha clasificación, Torre Cantalapiedra (2018) analiza los textos informativos de la migración centroamericana en tránsito por México; encuentra que los actores estatales fueron aludidos en un mayor número de ocasiones y de un modo tal por el periodismo de rutina que se infiere que son el actor social, además de los propios periodistas, con más poder sobre y en el discurso periodístico.

En cualquier caso, los periodistas no son meros transmisores de información, también orientan el texto (Castagnani y Colorado, 2009). Independientemente del tipo de cita, directa o indirecta, reproducir o referir un discurso implica su manipulación por parte del sujeto locutor-reproductor; éste hace uso de las situaciones discursivas ajenas para definir el discurso propio, por tanto, las interpreta e introduce su propia subjetividad (Méndez, 1999). La presencia de voces de otros actores sociales en los textos informativos supone que los discursos periodísticos recuperan discursos ajenos o partes de éstos, por lo que resulta provechoso considerar en el análisis esa intertextualidad, así como la manera en 
que tales voces son tratadas en función del ejercicio de la profesión periodística. El propósito del estudio no es determinar quién es el autor intelectual del discurso plasmado en un texto, sino enriquecerlo teniendo presente la procedencia de la materia prima y cómo es tratada por los periodistas; tales elementos permiten inferir a quiénes favorecen determinados discursos.

\section{Coyotaje y representaciones en prensa}

\section{Coyotes y coyotaje}

Se denomina coyotes, polleros o traficantes de migrantes a las personas que ayudan a uno o más migrantes a cruzar una frontera o territorio de manera irregular a cambio de una cantidad de dinero. El coyotaje es una actividad sancionada por los Estados; además, ciertas prácticas del tráfico de personas ponen en riesgo la integridad física de los migrantes o incluso sus vidas. Aunque puede realizarse por un individuo aislado, investigaciones recientes muestran que por lo común son redes (organizaciones) simples o complejas, compuestas por varias personas, quienes conducen a los migrantes a través de fronteras y territorios de forma subrepticia (véase Izcara, 2014). El término coyotes comprende: 1. en el nivel individual, es decir, individuos que realizan coyotaje sean o no miembros de redes/organizaciones dedicadas a tal actividad; 2 . en el nivel de redes/organizaciones de coyotaje a las que pertenecen. ${ }^{5}$

En este trabajo se han adoptado ciertas nociones de coyote y coyotaje por ser operativas para el análisis, pero es preciso destacar que sobre su contenido no hay un consenso en la literatura. Las contradicciones entre los hallazgos de los estudios, que dotan de significados a dichos conceptos, responden al abordaje de distintos contextos temporales — se trata de procesos que cambian rápidamente a lo largo del tiempo_y espaciales, así como a poblaciones migrantes cuya movilidad se ve facilitada (Slack y Whiteford, 2011; Izcara, 2012).

${ }^{5}$ Izcara $(2012,2014)$ construye una tipología de redes teniendo en cuenta dos ejes (estacionalidad y complejidad): 1. Redes simples que operan de manera estacional apoyadas por empleadores estadounidenses, están conformadas por un líder y un número reducido de ayudantes. 2 . Redes simples que obran de modo sistemático o "coyotes locales de frontera», poseen un tamaño similar a las anteriores. 3. Redes complejas que actúan de forma sistemática, son más extensas que las anteriores, tienen una fuerte estructura jerárquica, el líder es el administrador y los ayudantes están más especializados; se dividen en líneas, que a su vez se conforman por células. 


\section{Representación mediática del coyotaje}

En el contexto norteamericano, Spener (2008), como parte de una investigación amplia acerca del coyotaje en el sur de Texas, manifiesta varias contradicciones entre las evidencias empíricas que encuentra en campo y las representaciones negativas que los funcionarios gubernamentales sostienen en cuanto al coyotaje. Expresa que las visiones funcionariales - que considera frecuentemente simplistas, exageradas y en ocasiones bastante engañosas - prevalecen en los medios de comunicación sobre las perspectivas de otros actores sociales: las voces de los migrantes y de los propios coyotes.

Según Spener (2008) es posible sintetizar la representación que los funcionarios hacen del coyotaje y los coyotes, y que retoman los medios de comunicación en los siguientes puntos: 1. los coyotes son denominados «contrabandistas» O «traficantes» que mueven víctimas pasivas y las tratan como «mercancía», lo que favorece su vinculación con otros fenómenos reprobados por la opinión pública; 2. los «contrabandistas» están motivados únicamente por la ambición y se despreocupan por el bienestar y la integridad física de los migrantes; 3. a raíz del aumento del control fronterizo el «contrabando» sería un negocio cada vez más sofisticado y redituable, operaría con menos organizaciones de mayor tamaño; 4. el crimen organizado que participa del tráfico de personas es una amenaza para la seguridad nacional de Estados Unidos.

Advierte también que son dos las razones por las cuales las visiones de los funcionarios de gobierno imperan sobre las de los demás actores sociales en la cobertura que hacen los medios de comunicación: primero, porque sus visiones son consideradas como dignas de convertirse en noticia y además disponen de infraestructuras de relaciones públicas; mientras que el objetivo de migrantes y coyotes es mantener su anonimato y continuar ocultos, por lo que tienen poco interés en difundir mensajes a través de tales medios. Segundo, porque los cruces de frontera facilitados por coyotes generalmente aparecen en las noticias cuando implican una muerte, accidente o algún arresto; en tanto que los relatos de acciones exitosas del coyotaje sólo surgen cuando los periodistas cuentan con tiempo y recursos para realizar reportajes de investigación a fondo.

Con relación a los discursos periodísticos en torno a la inmigración en España en los primeros semestres de 1996 y 1997, Nash (2005) analiza la cobertura del tráfico de personas en el Estrecho. Advierte que los medios de comunicación tuvieron un gran interés en el funcionamiento de las redes que efectuaban la 
actividad de tráfico de migrantes; a la vez, opina que el discurso periodístico creó una valoración negativa acerca de los traficantes, a los que distinguía de forma clara de los pasajeros - los migrantes a los que se facilitaba el cruce del Estrecho mediante algún tipo de embarcación.

Conforme a la autora, la impresión subyacente era que se había producido un cambio de perfil en los traficantes de personas: «el tráfico inicial más espontáneo que abarcaba pateras y pesqueros, que combinaban la actividad pesquera con el tráfico de personas, quedaba desplazado por la generalización de redes y mafias establecidas y organizaciones con ramificaciones internacionales» (Nash, 2005:40). Al igual que en la migración hacia Estados Unidos, la transformación de las redes de coyotaje sobresale en el contexto migratorio español, pero sin que se lleve a cabo una atribución explícita a que los textos periodísticos estén haciendo eco de los discursos de los actores estatales. Para Nash la información periodística respecto al fenómeno del tráfico de migrantes en el Estrecho mostraba su complejidad, pero no resolvía de forma clara la cuestión de las responsabilidades políticas, puesto que las autoridades españolas y marroquíes habrían evidenciado su permisividad hacia los traficantes.

Al abordar los discursos alusivos a trata y tráfico de personas, Simone y Aierbe (2010) encuentran que por lo general los textos periodísticos emplean dichas palabras como si fueran sinónimos a pesar de ser actividades muy distintas. Caracterizan la trata frente al tráfico por: 1. falta de consentimiento de las personas, 2. existencia de una continuidad en la acción y 3. ser un crimen contra la persona. Asimismo, remarcan que difuminar los rasgos característicos de ambos conceptos no sólo ocasiona la confusión de la opinión pública, sino que banaliza la lucha contra la trata, criminaliza la inmigración irregular y confiere a los gobiernos legitimidad para endurecer las políticas represivas contra la migración, entre otras. Con base en la revisión de la literatura sobre discursos de los medios que abordan al coyotaje se destacan puntos relevantes para el análisis: a) carácter dominante de los actores estatales en los discursos concernientes al coyotaje; b) predominio de una imagen negativa hacia los coyotes y el coyotaje; c) cada vez más se manifiesta como una actividad en manos del crimen organizado; d) se relaciona intrínsecamente con el debate relativo a las responsabilidades de los Estados en el fenómeno migratorio; e) tales discursos tienen consecuencias sociales, por lo que es importante determinar a quiénes perjudican o benefician. 


\section{Corpus de textos y cuestiones metodológicas}

El corpus de textos informativos se obtuvo en dos pasos. Se revisaron todos los textos informativos - e informativos con interpretación - referentes a la migración centroamericana en tránsito irregular por México, en los dos diarios de mayor tirada nacional: El Universal ("El gran diario de México») y Reforma ("Corazón de México»). ${ }^{6}$ Se revisaron página por página las secciones «Nación» y «Estados» de ambos periódicos de enero a diciembre de 2014, lapso en el que se publicó un total de 281 textos (124 en El Universal y 157 en Reforma).? Esas notas permitieron tener una perspectiva amplia de la cobertura que dichos periódicos dieron a la migración centroamericana en tránsito irregular por México en el año de la crisis de los NNAM. De aquella cantidad se seleccionaron los textos con referencia al coyotaje (16) o que incluyesen alusiones a él (32); para analizar su contenido se tuvieron en cuenta las voces de los actores sociales mediante citas directas e indirectas.

En la gráfica 1 se aprecia cómo en la gran mayoría de las notas seleccionadas tiene cabida la voz de al menos un actor social, aparte de la del periodista. Resaltan los actores estatales extranjeros y los nacionales con 35.4 y 31.3 por ciento de los textos respectivamente. Este acceso de los actores estatales recalca el predominio que poseen en los discursos sobre coyotaje. Las voces de los coyotes sólo aparecen como principal fuente de los textos en dos ocasiones (4.2 por ciento). Por su parte, la voz de los defensores de los migrantes (12.5 por ciento) ocupa el tercer lugar en cuanto a presencia en dicha selección, pero a gran distancia de los actores estatales.

\footnotetext{
${ }^{6}$ Se escogieron estos dos periódicos por su amplia difusión y sus diferencias editoriales e ideológicas (Zepeda, 2005), lo que permite tener una imagen más completa de la prensa nacional mexicana.

${ }^{7}$ En el caso de Reforma debe considerarse que el apartado "Estados» se presenta como una subsección de "Nación». Aunque ambos periódicos no siguen necesariamente las mismas reglas para clasificar las noticias dentro de esas dos secciones, el contenido en sendas publicaciones es similar.
} 


\section{GRÁFICA 1}

Distribución porcentual de la presencia de voces de los actores sociales en los textos sobre coyotaje o que refieren al mismo, 2014

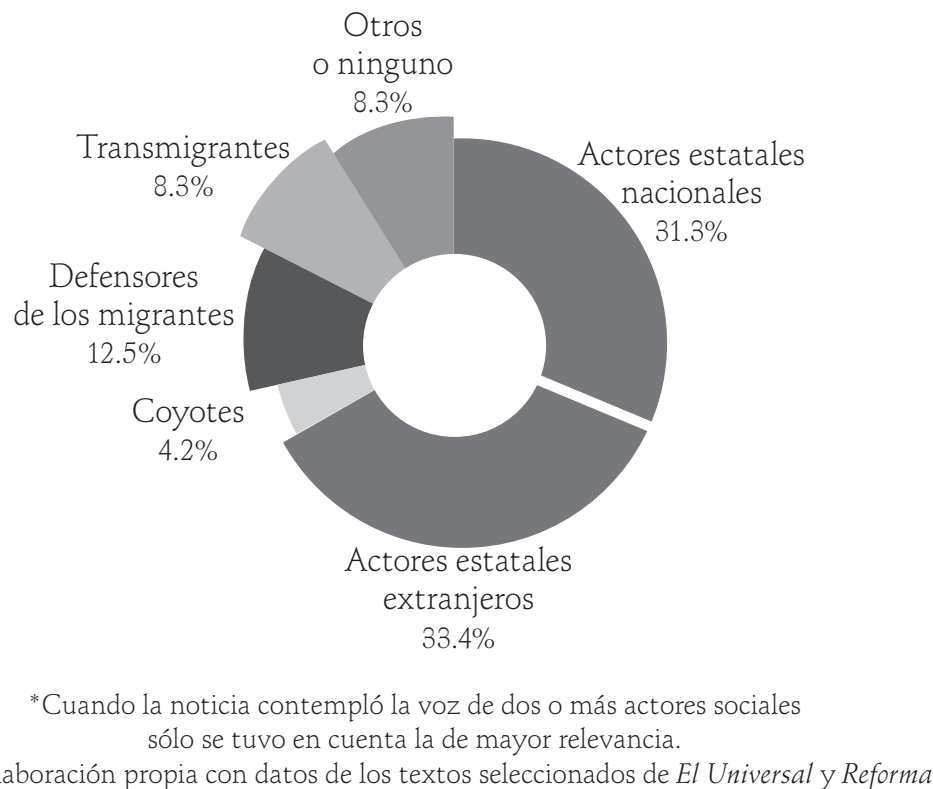

Fuente: elaboración propia con datos de los textos seleccionados de El Universal y Reforma.

La elección del año 2014 para realizar la investigación se debe a dos razones: primero, la denominada crisis de los NNAM $^{8}$ supuso que la cifra de noticias acerca de la migración centroamericana en tránsito irregular se elevase de modo considerable con relación a años precedentes (Torre, 2018); segundo, las crisis son circunstancias especialmente proclives para investigar los fenómenos sociales. En este caso la crisis de NNAM se ligó a la actividad del coyotaje, lo que provocó que se hicieran reportajes de esa temática y que incluso se recuperara la voz de los coyotes. La gráfica 2 muestra un auge en las cifras de noticias en los meses de junio, julio y agosto, debido a que la crisis humanitaria de los NNAM alcanza su mayor relevancia mediática. Esos tres meses acumulan más de la mitad (33) de los textos informativos referidos al coyotaje.

${ }^{8}$ La crisis de los NNAM consistió en un auge significativo en la cifra de menores mexicanos y centroamericanos que migraban hacia territorio estadounidense de manera irregular. 


\section{GRÁFICA 2}

Volumen de textos informativos respecto a la transmigración centroamericana clandestina en ambos periódicos, 2014

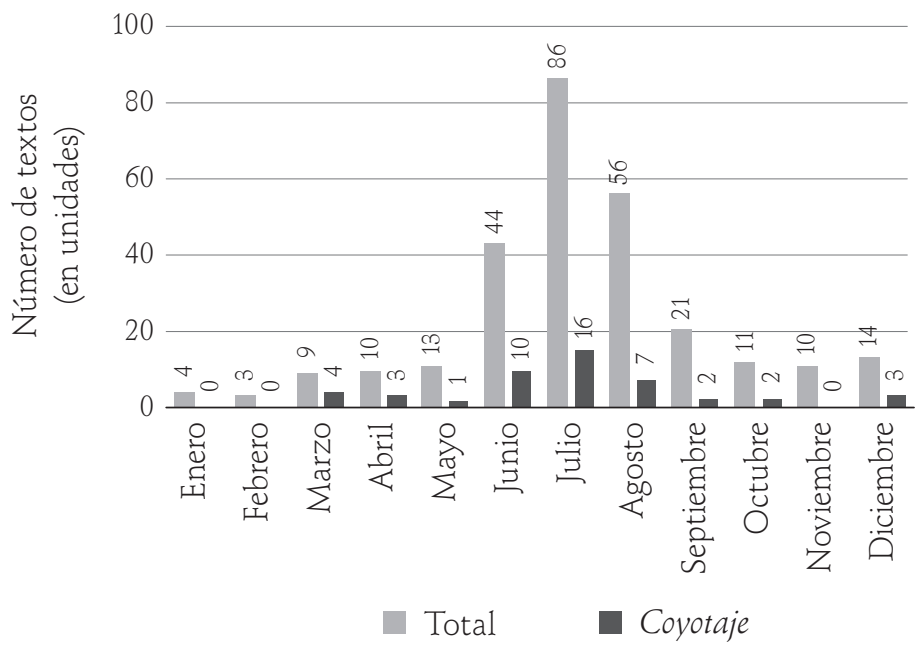

Fuente: elaboración propia con datos de los textos seleccionados de El Universal y Reforma.

168

\section{Representaciones en la prensa nacional durante 2014}

Los coyotes

La visión que prevalece acerca de los coyotes en los textos analizados es la de criminales que buscan lucrar con los migrantes, estos últimos retratados como víctimas ingenuas. Asimismo, se les caracteriza como personas que no son de fiar, que engañan y abandonan a los migrantes. Las voces de los actores estatales son las que tienen mayor presencia en los textos que construyen la imagen de los coyotes.

En un reportaje de investigación publicado en el mes de julio, el de mayor efervescencia mediática de la crisis de los NNAM, se muestran los resultados de una serie de entrevistas encubiertas efectuadas a coyotes guatemaltecos. Desde los primeros párrafos queda patente la ambición económica de los entrevistados: «Nosotros cobramos 6 mil dólares: mil 500 aquí, mil en Villahermosa y 3 mil 500 en la frontera» (Castellanos, 29 de julio de 2014). La manera en que el reportaje narra los encuentros con tales coyotes, el hecho de que se les denomine 
"traficantes» y que se refiera al primero de ellos por su apodo ("El Chuluyo») ofrece una imagen de éstos como sujetos realmente peligrosos.

De acuerdo con los textos examinados, el afán de lucro de esos ambiciosos criminales les conduciría a engañar a los migrantes para sacarles el máximo provecho. Diversas notas recuperan las voces de funcionarios públicos de diferentes países que señalan la argucia utilizada por los coyotes para aprovecharse de los migrantes: el canciller de Guatemala «indicó que los coyotes vendieron la idea en Centroamérica de que los niños pueden llegar a Estados Unidos y ser reunificados, pues no pueden permanecer bajo el resguardo de la Patrulla Fronteriza por más de 72 horas» (Garduño y Corona, 15 de julio de 2014a).

En otro reportaje publicado en dicho mes, en pleno boom mediático de la crisis migratoria, titulado "Los coyotes les quitan hasta sus casas» (Castellanos, 30 de julio de 2014), se ofrecen más elementos para reforzar su imagen como criminales peligrosos y avariciosos: el momento del cobro de sus servicios. El reportaje narra la historia de migrantes guatemaltecos que podrían perder sus casas por las deudas contraídas para sufragar los viajes de uno o varios de los miembros de su familia a Estados Unidos. En caso de no pagar los migrantes acabarían siendo víctimas de los coyotes a los que deben sus «honorarios».

Los textos estudiados representan a los coyotes como personas desleales y poco confiables, puesto que engañan, lucran, incumplen lo pactado y son capaces de abandonar a los migrantes menores de edad. El secretario del Departamento de Seguridad Nacional de Estados Unidos advirtió que "[las] familias ponen en grave riesgo a sus hijos al confiarlos a las redes de traficantes» (Hernández, 13 de junio de 2014). Además, en una nota que inserta un reportaje del Instituto Nacional de Migración, se menciona que «del total [de 370], 163 viajaban sin familiares y fueron abandonados por los traficantes» ("Detienen en 8 días», 30 de marzo de 2014). Lo anterior enfatiza circunstancias conflictivas en la relación coyotes-migrantes: cuando los primeros engañan y abandonan a los segundos. En cambio, las situaciones en que la contratación de los servicios de los coyotes resultan exitosas no se reflejan en la muestra.

\section{Representación alternativa del coyotaje}

De manera excepcional la prensa mexicana dio cabida a las voces de los propios coyotes; inclusive recopila cómo entienden su profesión y cómo se consideran a sí mismos polleros. Meses antes del boom mediático de la crisis de los NNAM, un 
reportaje recoge la historia de Carlos Salazar, un coyote en el estado de Baja California.

[Carlos señala] que desde los 14 años ha cruzado a más de 7 mil personas a Estados Unidos. Se considera un hombre honesto «un coyote viejo» que ha ayudado a miles [a] alcanzar el sueño de una vida mejor (...) Les cobraba barato desde que empecé el negocio, es más, a veces nada y hasta le compraba la comida de mi dinero. El gobierno no tiene nada que decir, la gente venía llorando y rogándome que la ayudara y eso hice durante tantos años (Sánchez, 22 de marzo de 2014).

Aunque ello sólo representa una fracción de los "coyotes de frontera», en un tiempo y espacio determinados, revela que la consideración de los coyotes de sí mismos y de su negocio puede ser muy diferente de la que se construye a través de los discursos de los actores gubernamentales. Carlos hace hincapié en su hospitalidad, honestidad y humanidad; elabora, de manera más o menos consciente, un discurso alternativo o discrepante al que impera en la prensa mexicana dominado por actores estatales, en el que se caracteriza al coyote de modo peyorativo.

El coyotaje

La percepción del coyotaje en los escritos analizados es la de una labor lucrativa que recurre al engaño para sacar partido de la ingenuidad de los migrantes, lo que genera situaciones de crisis migratoria. Dicha actividad es considerada un negocio ilícito que se asocia con otros y se encuentra en manos del crimen organizado.

Engaño

Las voces de funcionarios públicos de México, Estados Unidos y los países del Triángulo Norte de Centroamérica en tales textos confieren al coyotaje la responsabilidad sobre las crisis de los NNAM en mayor o menor grado; recalcan que la causa del auge en la cifra de menores migrantes es en gran medida resultado de una publicidad engañosa que los coyotes desarrollaron para inmigrantes desinformados. El embajador de Honduras en México «asocia el incremento de la migración infantil a una «campaña publicitaria patrocinada por pandilleros 
de la Mara, los polleros y el crimen organizado para hacer creer a los hondureños en Estados Unidos que podrán regularizar a sus hijos menores de edad si se aprueba la reforma migratoria» (Garduño, 4 de julio de 2014). Asimismo, para el canciller de Guatemala: «los coyotes vendieron la idea en Centroamérica de que los niños pueden llegar a Estados Unidos y ser reunificados» (Garduño y Corona, 15 de julio de 2014a).

Como se aprecia, los coyotes son referidos en un sentido figurado como publicistas abusivos en cuya red caen víctimas los migrantes, pues realizan «campañas de publicidad» donde se «venden ideas» $y$ «hacen creer» que sus hijos podrán llegar a Estados Unidos, ser regularizados y reunificados mediante el producto que ofrecen: los servicios de facilitación de cruce irregular de territorios y fronteras. El hecho de que ciertos discursos atribuyan la responsabilidad de la crisis de los NNAM a los coyotes no terminaría con el debate sobre la responsabilidad de los Estados, en la medida en que muestran su permisividad con la actividad. Por ello cabría esperar que los funcionarios públicos tuvieran interés en aparecer en los medios de comunicación para informar que están emprendiendo medidas para enfrentar ese negocio. Los titulares de dos noticias en plena crisis migratoria apoyan tal hipótesis.

A principios del mes de julio de 2014 el encabezado de un texto recopila una declaración en una entrevista realizada al embajador de Estados Unidos en México: "Nos activaremos contra los traficantes de menores» (Aponte, 2 de julio de 2014); mientras que en otro el canciller mexicano advierte: «México y CA harán frente a traficantes de personas» (Gómez y Benavides, 9 de julio de 2014). Todas esas noticias acerca de la confrontación de los Estados con los traficantes de personas, en el contexto de la crisis de los NNAM, refuerzan la idea de que los coyotes son en gran medida sus causantes.

Cabe mencionar que si bien existe un conjunto de noticias que destaca el papel que podrían haber desempeñado los coyotes en la generación y exacerbación de la crisis de NNAM, no es menos cierto que los textos informativos de los periódicos han enunciado de manera reiterada tres factores de fondo que explican la migración: «[Alejandro Hernández, redactor del primer informe de la CNDH sobre secuestro de migrantes] expuso que los menores han sido expulsados de sus países por tres factores: la situación económica, la violencia y la reunificación familiar» (Domínguez, 15 de noviembre de 2014). Los dos últimos factores han ocupado un lugar más destacado en los debates respecto a las causas de la migración de los menores; algunos titulares subrayan la violencia: «Migran niños por 
violencia» (Alcántara, 17 de junio de 2014) o «Huyen de los «maras» niñas salvadoreñas» (Domínguez, 30 de junio de 2014); y otros la reunificación familiar: «Perciben cancilleres crisis por reunificación» (Garduño, 2 de julio de 2014).

\section{Negocio}

Es frecuente que en los textos relativos al coyotaje se resalte su carácter lucrativo al indicar las tarifas que los coyotes cobran por cada migrante adulto o menor. En el reportaje antes mencionado se plantea que el coyotaje de los NNAM centroamericanos a Estados Unidos en tiempos de crisis puede ser muy lucrativo. El texto se titula «El negocio de llevar niños a Estados Unidos» y su antetítulo es «Coyotes» ganan con crisis migratoria [de los NNAM]» (Castellanos, 29 de julio de 2014). En el cuerpo de la noticia se hace un esfuerzo por calcular las cifras del negocio:

[El coyote] dijo que en cada viaje transportaba de 12 a 14 menores. Este era el segundo del mes. En esas dos jornadas su red de tráfico obtendría unos 156 mil dólares (dos millones de pesos). Organizaciones y albergues que asisten a menores repatriados en Tamaulipas, Chiapas, Honduras y Guatemala consultados por este diario estiman que al menos 75 por ciento de los que migran no acompañados a Estados Unidos van con coyote (Castellanos, 29 de julio de 2014).

Posteriormente se llevó a cabo una nueva estimación, esta vez para el negocio del coyotaje durante la crisis económica; se obtuvo el siguiente resultado: «Cálculo conservador: si 75 por ciento de los 56 mil 547 menores detenidos pagaron 5 mil dólares por persona, las ganancias para la delincuencia organizada fueron unos 212 millones de dólares (unos 2 mil 700 millones de pesos)» (Castellanos, 29 de julio de 2014). Pocos textos retoman los costos y riesgos en los que incurren los coyotes al desplegar su actividad: tiempo que dedican, años en prisión que tendrían que pasar al ser detenidos y enjuiciados, cuotas que deben pagar en muchos casos al crimen organizado.

En contraposición a la imagen del coyotaje como negocio muy lucrativo, los textos informativos destacan los infortunios económicos de los migrantes, los cuales pierden importantes sumas de dinero pagadas a los coyotes: "Los padres de esos niños, muchos radicados en Estados Unidos, pagaron a los coyotes entre 5 a 9 mil dólares, dinero que nunca recuperarán» (Martín, 14 de junio de 2014). A 
pesar de que las notas explícita o implícitamente reconocen que acudir al coyotaje es una estrategia que utilizan miles de familias migrantes centroamericanas, no muestran los casos en los que las «inversiones» obtuvieron buenos resultados.

\section{Crimen organizado}

En dichos escritos el coyotaje se asocia con el crimen organizado de diversas maneras; en primer lugar, varios textos afirman que está en sus manos: «Fuentes consultadas en la frontera confirmaron que la mayoría de los menores centroamericanos son transportados por delincuentes relacionados con el narcotráfico» (Villarino, 12 de junio de 2014). Por su parte, Jeffrey Sachs indica que «esas mismas redes criminales transnacionales [que se generaron en la década de los 1980] lucran con la gente más vulnerable, trasladándola hasta Estados Unidos» (Garduño y Corona, 15 de julio de 2014b). En segundo lugar, existen notas que mediante yuxtaposiciones constantes asocian al tráfico de personas con otras actividades delictivas de mayor gravedad operadas por el crimen organizado (tráfico de drogas y armas, trata de personas, entre otras): «Es un fenómeno migratorio regional derivado del tráfico de drogas, armas y personas» (Domínguez, 29 de junio de 2014). «Se fortalecerán las tareas de investigación para desarticular las redes de tráfico y trata, a través de la clausura de giros negros» (Garduño, 26 de agosto de 2014). «No es fácil trabajar con el tráfico de personas, drogas y a pesar de ello mantener un trato diferencial con nuestros niños señaló Rosa María Leal Pérez, primera dama guatemalteca» (Notimex, 4 de julio de 2014). "Las acciones contra el crimen prevén fortalecer las tareas de investigación e inteligencia para combatir el tráfico y la trata de personas, así como la operación de pandillas y otras organizaciones criminales» (Notimex, 26 de agosto de 2014, las cursivas son mías).

Tales yuxtaposiciones pueden considerarse incorrectas en la medida en que la gravedad de esos delitos es diferente, especialmente en los casos en que los coyotes no están involucrados en actividades delictivas aparte de la facilitación del cruce de fronteras. En tercer lugar, los textos favorecen la confusión entre los términos trata y tráfico; mientras que en unas ocasiones se refieren a las dos como actividades distintas, en otras se emplea el término tráfico como concepto genérico que incluiría al de trata. Se sobreentiende que el lector conoce el significado de ambas prácticas delictivas, por lo que no es necesario puntualizar el significado. Como se observa, los textos analizados asocian de manera efectiva el tráfico de personas con el crimen organizado; sin embargo, apenas 
ofrecen información acerca de la forma en que se producen nexos entre el coyotaje y otras labores criminales o las actividades que despliegan los coyotes además del coyotaje. Cuando lo hacen muestran información incompleta e imprecisa.

\section{Conclusiones}

La gran mayoría de las notas seleccionadas de El Universal y Reforma destaca características y acciones que revelan una imagen negativa de los coyotes y el coyotaje. Esta percepción puede deberse a las siguientes razones. Primero, el predominio de los actores estatales en los textos que refieren a los coyotes y el coyotaje - en la lógica del periodismo de rutina, numerosos textos dan cabida a información proporcionada por fuentes oficiales gubernamentales-, ya que los funcionarios públicos sostienen un discurso negativo frente a esa actividad y sus protagonistas. Los Estados se oponen al coyotaje e imponen fuertes sanciones a quienes lo despliegan, pues el hecho de que los coyotes faciliten el cruce de fronteras a los migrantes desafía el derecho soberano que tienen de decidir a quién dejan entrar o no en su territorio, consagrado por las legislaciones nacionales e internacionales. La idea peyorativa de los funcionarios públicos acerca de los coyotes posibilitaría la adhesión de la ciudadanía a la causa anticoyotaje, a la vez que legitimaría el uso de más recursos para combatir la práctica.

Segundo, los periodistas, quienes no son necesariamente expertos en la materia migratoria, no tienen más referentes para conceptualizar a los coyotes y al coyotaje que los proporcionados por los actores estatales; retomar otras alternativas requeriría que el periodista le dedicara tiempo y recursos de los que por lo habitual no dispone. Además, serían visiones de la realidad menos conocidas y compartidas por los lectores, lo que las hace menos deseables para la actividad periodística que pretende llegar a audiencias amplias. Tercero, en el ejercicio de esta profesión se prima lo dramático, lo imprevisible, lo catastrófico, es decir, cuanto más elevado sea el componente negativo más noticiable es el acontecimiento, en concreto en los últimos años con la tendencia hacia la espectacularización y el sensacionalismo de la práctica (Gómez-Escalonilla y Santín, 2012).

Las similitudes entre los hallazgos de esta investigación y los de otras en distintos tiempos y contextos - principalmente en cuanto a la imagen negativa de los coyotes y el carácter dominante de la visión de actores estatales - exponen la dependencia de los medios de comunicación de nociones sesgadas, incompletas 
y simplificadoras de la realidad de los coyotes y el coyotaje ofrecidas por dichos actores; construcciones sociales que adquirieron un grado de rigidez y permanencia que dificulta la captación de las rápidas transformaciones que ha experimentado el fenómeno a lo largo del tiempo. Por ello, es importante que las organizaciones de la sociedad civil, academia, organismos internacionales, entre otros, lleven a cabo investigaciones cuantitativas y cualitativas que aporten visiones alternativas más objetivas, completas y diversas del tema. En particular, la relación entre coyotaje y crimen organizado es un tópico de gran relevancia, pero sobre el cual existe confusión.

Una de las novedades más notables del presente trabajo es que permite evidenciar un discurso que apunta a los coyotes y al coyotaje como responsables de la crisis migratoria de los NNAM de 2014, al menos como promotores del auge en los flujos. ¿̇Se trata de chivos expiatorios? La explicación relativa al incremento de la migración de los NNAM, sea cierta o falaz, favorece el enmascaramiento de las causas estructurales de la migración: las condiciones de vida en los países centroamericanos (situación de violencia, precariedad económica, etcétera) y la reunificación familiar. Sobre todas ellas los Estados tienen responsabilidades políticas. El pago de fuertes sumas de dinero a los coyotes y los riesgos que los migrantes asumen no pueden asociarse sólo a la oferta de servicios de coyotaje, es preciso examinar las razones por las que existe una alta demanda de esos servicios.

El hecho de que los discursos periodísticos señalen al coyotaje como negocio que vive del engaño a los migrantes y que está vinculado al crimen organizado -ya sea de manera poco fundamentada - , permite a los Estados justificar el empleo de más medios para combatir la práctica del coyotaje; ello significa disponer de más medios en contra de los migrantes irregulares y facilitar su detección y detención. Asimismo, son textos que pretenden desincentivar que los migrantes acudan a los coyotes con la intención de facilitar el cruce de fronteras y territorios; esta percepción funesta del coyotaje contrasta con la propuesta de Spener (2008), para quien constituye una estrategia de cruce de fronteras y de supervivencia de los migrantes, un acto de resistencia activa frente al confinamiento territorial en una región del mundo económicamente deprimida. En esta visión del coyotaje es posible afirmar que el discurso desfavorable relativo a los coyotes es en buena medida antiinmigrante, dado que se ataca una de la estrategias al alcance de los migrantes para superar las adversidades presentes en sus países de origen o lograr la ansiada reunificación de muchas familias. 


\section{Referencias}

Adoni, Hanna y Sherrill Mane (1984), "Media and the social construction of reality. Toward an integration of theory and research», Communication Research, 11(3), pp. 323-340.

Alcántara, Liliana (17 de junio de 2014), "Migran niños por violencia», El Universal.

Andreas, Peter (2001), "The transformation of migrant smuggling across the US-Mexican border», en David Kyle y Rey Koslowski (eds.), Global human smuggling. Comparative perspectives, Baltimore, Johns Hopkins University Press, pp. 107-125.

Aponte, David (2 de julio de 2014), "Nos activaremos contra traficantes de menores», El Universal.

Caminos Marcet, José María (1997), Periodismo de investigación. Teoría y práctica, España, Síntesis.

Castagnani, Tiziana y César Colorado (2009), «La representación de la mujer inmigrante en la prensa escrita española. Análisis del discurso citado en textos periodísticos», Discurso \& Sociedad, 3(4), pp. 621-657.

Castellanos, Laura (29 de julio de 2014), "El negocio de llevar niños a EU», El Universal. (30 de julio de 2014), "Los «coyotes» les quitan hasta sus casas», El Universal.

Congreso de la Unión de los Estados Unidos Mexicanos (2017), Ley de Migración 2011, en http://www.diputados.gob.mx/LeyesBiblio/ref/Imigra.htm

De Fleur, Melvin L. y Sandra J. Ball-Rokeach (1993), Teoría de la comunicación de masas: nueva edición revisada y ampliada, Barcelona, Paidós Ibérica.

«Detienen en 8 días a 370 niños migrantes» (30 de marzo de 2014), Reforma.

Dolfin, Sarah y Garance Genicot (2010), «What do networks do? The role of networks on migration and (coyotes use», Review of Development Economics, 14(2), pp. 343-359.

Domínguez, Miguel (29 de junio de 2014), «Espera Honduras a deportados», Reforma. (30 de junio de 2014), «Huyen de los «maras» niñas salvadoreñas», Reforma.

Domínguez, Miriam (15 de noviembre de 2014), «Crecen casos de niños migrantes», El Universal.

Garduño, Silvia (2 de julio de 2014), "Perciben cancilleres crisis por reunificación», Reforma.

(4 de julio de 2014), «Nos sorprendió tsunami migratorio», Reforma. (26 de agosto de 2014), "Evitan a migrantes acceso a «La Bestia», Reforma.

Garduño, Silvia y Emily Corona (15 de julio de 2014a), «Atribuye Guatemala emergencia a 〈coyotes»», Reforma.

(15 de julio de 2014b), «Es Centroamérica zona de Guerra», Reforma. 
Genette, Gérard (1989), Palimpsestos. La literatura en segundo grado, España, Taurus.

Gómez Escalonilla, Gloria y Marina Santín Durán (2012), «Los medios inmigrantes como referentes de certidumbre social. Análisis de la prensa latina en las capitales de EE.UU. y España", Prisma Social. Revista de Investigación Social (8), pp. 49-86.

Gómez, Natalia y Carlos Benavides (9 de julio de 2014), «México y CA harán frente a traficantes de personas», El Universal.

Hernández, J. Jaime (13 de junio de 2014), «Indagará EU abusos a niños migrantes», El Universal.

Izcara Palacios, Simón Pedro (2012), «Coyotaje y grupos delictivos en Tamaulipas», Latin American Research Review, 47(3), pp. 41-61.

(2014), "La contracción de las redes de contrabando de migrantes en México», Revista de Estudios Sociales, (48), pp. 84-99.

Martín, Fredy (14 de junio de 2014), «Irnos para el norte... esa es nuestra vida», El Universal.

Méndez García de Paredes, Elena (1999), «La literalidad de la cita en los textos periodísticos», Revista Española de Lingüística, 30(1), pp. 147-167.

Nash, Mary (2005), Inmigrantes en nuestro espejo: inmigración y discurso periodístico en la prensa española, Barcelona, Icaria Antrazyt.

Notimex (4 de julio de 2014), "Reconocen trato humano en albergues», El Universal. (26 de agosto de 2014), "Buscan evitar el abordaje a «La Bestia», El Universal.

París Pombo, María Dolores (2016), «Trayectos peligrosos: inseguridad y movilidad humana en México», Papeles de Población, 22(90), pp. 145-172.

Rodrigo Alsina, Miquel (1989), La construcción de la noticia, Barcelona, Paidós.

Rodrigo Alsina, Miquel y Gaya Morla, Catalina (2001), «Medios de comunicación e interculturalidad», Cuadernos de Información (14), pp. 105-110, en http://cuadernos. info/index.php/CDI/article/view/186/797

Sánchez, Laura (22 de marzo de 2014), «Polleros〉 desempleados», El Universal.

Simone Fabbri, Marco y Peio Aierbe (2010), «Funcionalidad de los discursos sobre trata y tráfico de personas», en María Martínez Lirola (ed.), Migraciones, discursos e ideologías en una sociedad globalizada. Claves para su mejor comprensión, Alicante, Instituto Alicantino de Cultura Juan Gil-Albert, pp. 107-125.

Slack, Jeremy y Scott Whiteford (2011), «Violence and migration on the Arizona-Sonora border», Human Organization, 70(1), pp. 11-21.

Spener, David (2008), «El apartheid global, el coyotaje y el discurso de la migración clandestina: distinciones entre violencia personal, estructural y cultural», Migración y Desarrollo (10), pp. 127-156. 
Torre Cantalapiedra, Eduardo (2018), «Periodismo, actores sociales y migración: intertextualidad en los discursos periodísticos sobre migración», Convergencia. Revista de Ciencias Sociales (77), pp. 201-227.

Villarino, Ángel (12 de junio de 2014), "Abusan en frontera de niños migrantes», Reforma.

Zepeda Patterson, Jorge (2005), "La prensa en México o la soberbia de la víctima», Cuadernos de Periodistas. Revista de la Asociación de la Prensa de Madrid (2), pp. $145-151$. 